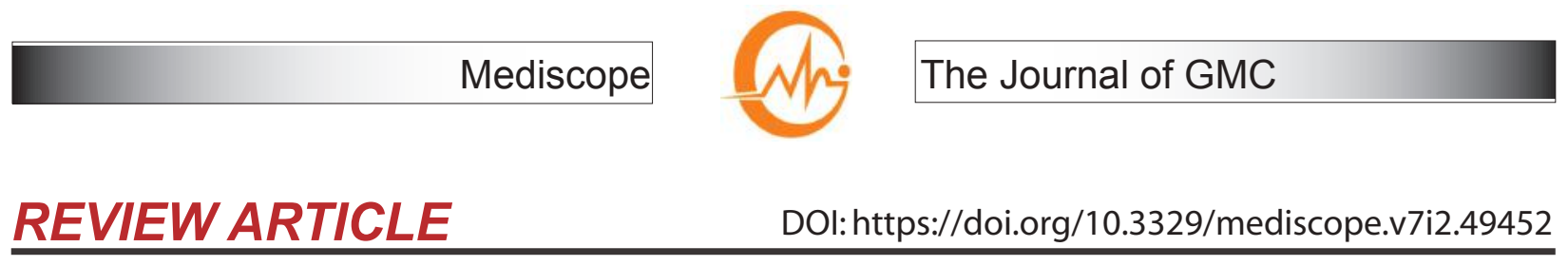

\title{
Gastro Coronavirus: A new era
}

\author{
MA Ahad ${ }^{1}$
}

\begin{abstract}
Coronavirus is a highly infectious contagious virus producing pandemic throughout the world with high morbidity and mortality. Right now, there is no vaccine to prevent human coronavirus infections. But you mayable to reduce your risk of getting or spreading an infection by-washing hands often with soap and water for at least 20 seconds, using an alcohol-based hand sanitizer that contains at least $70 \%$ alcohol if soap and water are not available, avoiding touching your face, nose, or mouth with unwashed hands, use of face mask, avoiding close contact with people who are sick. There is no specific treatment for coronavirus. Treatment aims to relieve the symptoms. Most people will get better on their own. However, you can relieve your symptoms by-taking over-the-counter medicines for pain, fever, and cough\&plenty of nutritious diet, drinking fluids and taking rest.
\end{abstract}

Keywords: Novel coronavirus, Gastro coronavirus, Pandemic, Contagious, COVID-19, SARS, MERS.

\section{Introduction}

How many could be suffering from 'Gastro Corona Virus' - the version of the deadly bug no one is talking about.A persistent dry cough and fever are the two main symptoms we know to look for, but scientists have said Covid-19 can attack our digestive systems as well.Coronaviruses are a group of viruses that cause diseases in mammals and birds. In humans, the viruses cause respiratory infections which are typically mild, including the common cold; however, rarer forms such as SARS, MERS and the novel Coronavirus causing the current outbreak can be lethal. In cows and pigs they may cause diarrhoea, while in chickens they can cause an upper respiratory disease. There are no vaccines or antiviral drugs that are approved for prevention or treatment.

Coronaviruses are viruses in the subfamily Orthocoronavirinae in the family Coronaviridae, in the order Nidovirales. ${ }^{1,2}$ Coronaviruses are enveloped viruses with a positivesense single-stranded RNA genome and with a nucleocapsid of helical symmetry. The genomic size of coronaviruses ranges from approximately 26 to 32 kilobases, the largest for an RNA virus. Human coronaviruses can cause -Severe acute respiratory syndrome (SARS) and Middle East respiratory syndrome.

1. Professor Dr. Md. Abdul Ahad, Professor of Gastroenterology \& Principal, Khulna Medical College, Khulna. Email: drahadbd@yahoo.com 


\section{Novel Coronavirus (COVID-19)}

\section{Discovery}

Coronaviruses were discovered in the $1960 \mathrm{~s} ;{ }^{3}$ the earliest ones discovered were infectious bronchitis virus in chickens and two viruses from the nasal cavities of human patients with the common cold that were subsequently named human coronavirus 229E and human coronavirus OC43. ${ }^{4}$ Other members of this family have since been identified, including SARS-CoV in 2003, HCoV NL63 in 2004, HKU1 in 2005, MERS-CoV in 2012, and 2019-NCOV in 2019; most of these have been involved in serious respiratory tract infections. In December 2019, a pneumonia outbreak was reported in Wuhan, China. ${ }^{5}$ On 31 December 2019, the outbreak was traced to a novel strain of coronavirus, which was labeled as 2019NCOV by the World Health Organization (WHO). ${ }^{6,7}$ According to Daniel Lucey at Georgetown University, the first human infections must have occurred in November 2019 or earlier. ${ }^{8}$ As of 30th January 2020 (16:00 UTC), there have been 214 confirmed deaths and more than 8,230 confirmed cases in the coronavirus pneumonia outbreak. ${ }^{9-12}$ The Wuhan strain has been identified as a new strain of Betacoronavirus from group 2B with an $\sim 70 \%$ genetic similarity to the SARSCOV.The virus was suspected to have originated in snakes, ${ }^{13}$ but many leading researchers disagree with this conclusion. ${ }^{14}$ Daniel Lucey, an infectious disease specialist at Georgetown University, stated that "Now it seems clear that the seafood market is not the only origin of the virus" 8,15

\section{Name and Morphology}

The name "Coronavirus" is derived from the Latin corona, meaning crown or halo, which refers to the characteristic appearance of the virus particles (virions): by electron microscopy, which have a fringe of large, bulbous surface projections creating an image reminiscent of a royal crown or of the solar corona. ${ }^{16}$ This morphology iscreated by the viral spike (S) peplomers, which are proteins that populate the surface of the virus and determine host tropism.

Transmissions

The main way the disease spreads is through respiratory droplets expelled by someone who is coughing. ${ }^{17}$ When someone coughs or sneezes they spray small liquid droplets from their nose or mouth which may contain virus. If you are too close, you can breathe in the droplets, including the COVID-19 virus if the person coughing has the disease. The risk of catching COVID-19 from someone with no symptoms at all is very low. Infectious diseases are caused by pathogenic microorganisms, such as bacteria, viruses, parasites or fungi; the diseases can be spread, directly or indirectly, from one person to another.

Analysis of specimens taken from the gastrointestinal tract of 95 COVID-19 patients has identified the virus in the oesophagus, stomach, duodenum and rectum. The virus also showed up in about half of the stool samples collected. The suggestion is that the gastrointestinal symptoms are caused by the virus invading the ACE2-containing cells that are found throughout the bowel. This together with the presence of the virus in the stool suggest the gastrointestinal tract as another possible route of infection and transmission. ${ }^{18}$ Current evidence on other coronavirus strains shows that while coronaviruses appear to be stable at low and freezing temperatures for a certain period, food hygiene and good food safety practices can prevent their transmission through food. People of all ages can be infected by the new coronavirus (2019-NCoV). Older people and people with pre-existing medical conditions (such as asthma, diabetes, heart disease, cancer) appear to be more vulnerable to becoming severely ill with the virus.WHO advises people of all ages to take steps to protect themselves from the virus, for example by following good hand hygiene and good respiratory hygiene.

\section{Human Coronaviruses}

Coronaviruses are believed to cause a significant percentage of all common colds in human adults and children.Coronaviruses 
cause colds with major symptoms, e.g. fever, sore throat, swollen adenoids, primarily in the winter and early spring seasons. Coronaviruses can cause pneumonia-either direct viral pneumonia or a secondary bacterial pneumonia. They can also cause bronchitis-either direct viral bronchitis or a secondary bacterial bronchitis ${ }^{19,20}$ The much publicized human coronavirus discovered in 2003, SARS-CoV which causes severe acute respiratory syndrome (SARS), has a unique pathogenesis because it causes both upper and lower respiratory tract infections. ${ }^{21}$

\section{Gastro Coronavirus}

Some people with the coronavirus have reported gastrointestinal symptoms including diarrhoea, nausea and vomiting. Estimates of how common these symptoms vary widely, from $1 \%$ to more than half of patients. For some people, the symptoms may be caused by prescribed antibiotics that can cause diarrhoea as a side effect. In fact, recent medical evidence from China and the United States also suggests there is a subset of gastrointestinal coronavirus patients who don't display the classic respiratory symptoms of the disease. ${ }^{18,22}$ For both elderly patients and children, Mahboubfar says gastrointestinal symptoms include acute diarrhea, abdominal spasms, stomachaches, nausea vomiting, and the loss of appetite and sense of smell.

\section{Symptoms}

The most common symptoms of COVID-19 are fever, tiredness, dry cough and breathing difficulties. Some patients may have headache, fatigue, aches and pains, nasal congestion, runny nose, sore throat or diarrhea with or without blood.Rare features are burning sensation in whole body, chills and rigor, cold body, new onset of severe anorexia and anosmia. Hepatic manifestations-the clinical presentation of COVID-19 may include hepatic manifestations such as acute hepatitis and abnormal liver biochemical tests. $^{23}$ These symptoms are usually mild and begin gradually. Some people become infected but don't develop any symptoms and don't feel unwell.In more severe cases infection can cause pneumonia, severe acute respiratory syndrome, and even death. The period within whichthe symptoms would appear is $2-14$ days.

\section{Diseases}

When a disease is new, there is no vaccine until one is developed. It can take a number of years for a new vaccine to be developed. Novel Coronavirus, is a new strain that was discovered in 2019 and has not been previously identified in humans.Women with COVID-19 can breastfeed if they wish to do so. They should practice respiratory hygiene during feeding wearing a mask where available, washing hands before and after touching the baby \& routine cleaning and disinfecting surfaces they have touched. The virus that causes COVID-19 and the one that caused the outbreak of Severe Acute Respiratory Syndrome (SARS) in 2003 are related to each other genetically, but the diseases they cause are quite different.We know it is possible for people of any age to be infected with the virus, but so far there are relatively few cases of COVID-19 reported among children.ICTV announced "severe acute respiratory syndrome coronavirus 2 (SARSCoV-2)" as the name of the new virus on 11 February 2020.

Coronaviruses are zoonotic, meaning they are transmitted between animals and people. It is not certain, how long the virus that causes COVID-19 survives on surfaces, but it seems to behave like other coronaviruses. Studies suggest that coronaviruses (including preliminary information on the COVID-19 virus) may persist on surfaces for a few hours or up to several days. Globally, about $3.4 \%$ of reported COVID-19 cases have died. By comparison, seasonal flu generally kills far less than $1 \%$ of that infected. COVID-19 can be characterized as a pandemic. This is due to the rapid increase in the number of cases outside China over the past 2 weeks that has affected a growing number of countries.Cold weather and snow cannot kill the new coronavirus. There is no reason to believe that cold 
weather can kill the new coronavirus or other diseases. COVID-19 virus can be transmitted in areas with hot and humid climates. From the evidence so far, the COVID-19 virus can be transmitted in allareas, including areas with hot and humid weather. Regardless of climate, adopt protective measures if you live in, or travel to an area reporting COVID-19. Coronaviruses are a large family of viruses that are known to cause illness ranging from the common cold to more severe diseases such as Middle East Respiratory Syndrome (MERS) and Severe Acute Respiratory Syndrome (SARS). ${ }^{21,24}$

Smokers are likely to be more vulnerable to COVID-19 as the act of smoking means that fingers (and possibly contaminated cigarettes) are in contact with lips which increases the possibility of transmission of virus from hand to mouth. Smokers may also already have lung disease or reduced lung capacity which would greatly increase risk of serious illness. Smoking products such as water pipes often involve the sharing of mouth pieces and hoses, which could facilitate the transmission of COVID-19 in communal and social settings.

\section{Gut invaders}

It is interesting to note that the first case of novel coronavirus reported in the US had two days of nausea and vomiting and episodes of diarrhoea in addition to their respiratory symptoms. The virus was detected in samples from this patient's nose, their throat but also isolated from stool samples collected.Analysis of specimens taken from the gastrointestinal tract of 95 COVID-19 patients has identified the virus in the oesophagus, stomach, duodenum and rectum. ${ }^{25}$ The virus also showed up in about half of the stool samples collected. The suggestion is that the gastrointestinal symptoms are caused by the virus invading the ACE2-containing cells that are found throughout the bowel. This together with the presence of the virus in the stool suggest the gastrointestinal tract as another possible route of infection and transmission. ${ }^{18}$ It appears that SARS-CoV-2 is detectable in the stool for several days after it has cleared from respiratory tract samples. So patients who have recovered from COVID-19 or are asymptomatic could be shedding virus into their stool without knowing it, potentially increasing the risk of transmission to others.

\section{IIIness Severity}

The largest cohort reported of $>44,000$ persons with COVID-19 from China showed that illness severity can range from mild to critical: Mild to moderate (mild symptoms up to mild pneumonia): $81 \%$; Severe (dyspnea, hypoxia, or $>50 \%$ lung involvement on imaging): $14 \%$; Critical (respiratory failure, shock, or multiorgan system dysfunction): $5 \% 26$

\section{Reinfection}

There are limited data about reinfection with SARS-CoV-2 after recovery from COVID19. ${ }^{27,28}$ While viral RNA shedding declines with resolution of symptoms, it may continue for days to weeks. ${ }^{29-31}$ However, the detection of RNA during convalescence does not necessarily indicate the presence of viable infectious virus. Clinical infection has been correlated with the detection of IgM and IgG antibodies. ${ }^{32-35}$ However, definitive data are lacking, and it remains uncertain whether individuals with antibodies are protected against reinfection with SARS-CoV-2, and if so, what concentration of antibodies is needed to confer protection.

\section{Diagnosis}

To make a diagnosis, health care providers take medical history, history of contact with corona patients, including symptoms. Also necessary are detailed physical examination, blood tests, lab tests of sputum, a sample from a throat swab, or other respiratory specimens.

\section{Viral Testing}

Diagnosis of COVID-19 requires detection of SARS-CoV-2 RNA by reverse transcription polymerase chain reaction (RT-PCR). Detection of SARS-CoV-2 viral RNA is better in 
nasopharynx samples compared to throat samples. ${ }^{36}$ Lower respiratory samples may have better yield than upper respiratory samples36 SARS-CoV-2 RNA has also been detected in stool and blood. ${ }^{37,38}$ Detection of SARS-CoV-2 RNA in blood may be a marker of severe illness. ${ }^{39}$ Viral RNA shedding may persist over longer periods among older persons and those who had severe illness requiring hospitalization (median range of viral shedding among hospitalized patients 12-20 days). ${ }^{40}$ Infection with both SARSCoV-2 and with other respiratory viruses has been reported, and detection of another respiratory pathogen does not rule out COVID-19.

\section{Laboratory Findings}

Lymphopenia is the most common laboratory finding in COVID-19, and is found in as many as $83 \%$ of hospitalized patients. ${ }^{41,42}$ Lymphopenia, neutrophilia, elevated serum alanine aminotransferase and aspartate aminotransferase levels, elevated lactate dehydrogenase, high CRP, and high ferritin levels may be associated with greater illness severity. ${ }^{43-}$ 45 Elevated D-dimer and lymphopenia have been associated with mortality. Procalcitonin is typically normal on admission, but may increase among those admitted to an ICU. ${ }^{46}$ Patients with critical illness had high plasma levels of inflammatory makers, suggesting potential immune dysregulation. ${ }^{47}$

\section{Radiographic Findings}

Chest radiographs of patients with COVID-19 typically demonstrate bilateral air-space consolidation, though patients may have unremarkable chest radiographs early in the disease. ${ }^{48}$ Chest CT images from patients with COVID-19 typically demonstrate bilateral, peripheral ground glass opacities. ${ }^{49,50}$ Because this chest CT imaging pattern is non-specific and overlaps with other infections, the diagnostic value of chest CT imaging for COVID-19 may be low and dependent upon radiographic interpretation. ${ }^{51,52}$ One study found that $56 \%$ of patients who presented within two days of diagnosis had a normal $\mathrm{CT}^{53}$ Conversely, other studies have identified chest CT abnormalities in patients prior to the detection of SARS-CoV-2 RNA. ${ }^{54}$ Given the variability in chest imaging findings, chest radiograph or CT alone is not recommended for the diagnosis of COVID-19.

\section{Treatment}

At the moment there is no specific treatment for the disease caused by the coronavirus. Treatment is limited to easing the symptoms.Symptoms from a coronavirus infection cannot be treated with antibiotics because antibiotics are only effective against bacteria, not against viruses.There is no specific treatment for coronavirus. Treatment aims to relieve the symptoms. Most people will get better on their own. However, you can relieve your symptoms by-taking over-thecounter medicines for pain, fever, and cough. Modalities of treatment are oral Favipravir, Injectable Remdesivir, Methylprednisolone or Dexamethasone, Enoxaparin, High flow oxygen, Ventilator etc. Using a room humidifier or taking a hot shower to help ease a sore throat and cough. Getting plenty of nutritious diet, drinking fluids and taking rest.No, antibiotics do not work against viruses. The 2019NCOV is a virus and, therefore, antibiotics should not be used as a means of prevention or treatment.

\section{Prevention}

Right now, there is no vaccine to prevent human coronavirus infections. But a person may be able to reduce risk of getting or spreading an infection by- Washing hands often with soap and water for at least 20 seconds, an alcohol-based hand sanitizer that contains at least $70 \%$ alcohol if soap and water are not available, avoiding touching the face, nose, or mouth with unwashed hands, use of face mask, avoiding close contact with people who are sick, mass gatherings, cleaning and disinfecting surfaces that are frequently touched, covering coughs and sneezes with a tissue followed by throwing away the tissue and then washing hands. Staying home when sick. 


\section{Conclusion}

GI manifestations are not uncommon in patients with COVID-19 infection and with passage of time they are more frequently being reported. In fact, a subgroup of these cases might present with pure GI symptoms. Fecal shedding of the virus and its detection not only establishes the GIT involvement by the virus but also highlights a potential source of spread-feco-oral transmission. More data are needed to come to concrete management decisions on difficult situations such as IBD with COVID infection. During this time of coronavirus pandemic, as more and more data and evidences keep pouring in, we, gastroenterologists, have to unlearn many older habits and learn a few new ones to protect ourselves and our patients. The principle should be "primum non nocere"- do no harm. Catching up with the vast knowledge that pours in everyday about this virus and management protocols, we have to tread our path more carefully.

GI symptoms are commonly encountered in hospitalized COVID-19 patients. GI symptoms were not associated with poorer outcomes such as increased mortality, longer hospital LOS, and increased mechanical intubation in COVID-19 patients. It appears that the GI symptoms could potentially be a bystander in patients with COVID-19. Further, more extensive studies are needed to evaluate the effects of $\mathrm{Gl}$ symptoms on outcomes in COVID-19.

Avoiding close contact with people suffering from acute respiratory infections. Frequent hand-washing, especially after direct contact with ill people or their environment.Avoiding unprotected contact with farm or wild animals.People with symptoms of acute respiratory infection should practice cough etiquette. WHO does not recommend any specific health measures for travelers. In case of symptoms suggestive of respiratory illness either during or after travel, the travelers are encouraged to seek medical attention and share their travel history with their health care provider. Proper nutrition and hydration are vital. People who eat a well-balanced diet tend to be healthier with stronger immune systems and lower risk of chronic illnesses and infectious diseases. So should eat a variety of fresh and unprocessed foods every day to get the vitamins, minerals, dietary fibre, protein and antioxidants, drink enough water.

\section{Acknowledgement}

I am praying for those COVID-19 patients who sacrificed their lives during this pandemic. I am grateful to the respected COVID-19 fighters (doctors, health workers and other professionals), those who dedicated their lives in this war against invisible enemy and I pray for their departed souls.

\section{References}

1. Jump up to:a b de Groot RJ, Baker SC, Baric R, Enjuanes L, Gorbalenya AE, Holmes KV, Perlman S,Poon L,Rottier PJ, TalbotPJ, Woo PC, Ziebuhr J (2011). "Family Coronaviridae". In AMQ King, E Lefkowitz, MJ Adams, EB Carstens (eds.). Ninth Report of the International Committee on Taxonomy of Viruses. Elsevier, Oxford. pp.806-828.

2. International Committee on Taxonomy of Viruses (24 August 2010). "ICTV Master Species List 2009 - v10" (xls).

3. "Coronavirus: Common Symptoms, Preventive Measures, \& How to Diagnose It". Caringly Yours. 28 January 2020. Retrieved 28 January2020.

4. Geller C, Varbanov M, Duval RE (November 2012). "Human coronaviruses: insights into environmental resistance and its influence on the development of new antiseptic strategies".

Viruses. 4 (11): 3044-3068.

5. "2019 Novel Coronavirus infection (Wuhan, China): Outbreak update". Canada.ca. 21 January 2020.

6. Jump up to:a b "Laboratory testing of human suspected cases of novel coronavirus (nCoV) infection. Interim guidance, 10 January 2020" (PDF). Archived (PDF) from the original on 20 January 2020. 
Retrieved 14 January 2020.

7. Jump up to:a b c "Novel Coronavirus 2019, Wuhan, China CDC". www.cdc. gov.23 January 2020. Archived from the original on 20 January 2020.Retrieved 23 January 2020.

8. Jump up to:a b Cohen, Jon (26 January 2020). "Wuhan seafood market may not be source of novel virus spreading globally". ScienceMag American Association for the Advancement of Science. (AAAS). Archived from the original on 27 January 2020. Retrieved 29 January 2020.

9. "Operations Dashboard for ArcGIS". gisanddata. maps.arcgis.com. The Center for Systems Science and Engineering (CSSE) is a research collective housed within the Department of Civil and Systems Engineering (CaSE) at Johns Hopkins University (JHU). 28 January 2020. Archived from the original on 28 January 2020. Retrieved 28 January 2020.

10. Kotyk, Alyse (28 January 2020). "B.C. confirms province's first presumptive positive case of new coronavirus". CTV News. Archived from the original on 28 January 2020. Retrieved 28 January2020.

11. James Griffiths; Nectar Gan; Tara John; Amir Vera. "Wuhan coronavirus death toll rises, as city imposes transport lockdown". CNN.

12. "China virus death toll mounts to 25 , infections spread". Reuters. 24 January2020. Retrieved 24 January 2020.

13. "No, the Wuhan Virus Is Not a 'Snake Flu'". Wired. Archived from the original on 24 January 2020. Retrieved 24 January 2020.

14. Eschner, Kat (28 January 2020). "We're still not sure where the Wuhan coronavirus really came from". Popular Science. Archivedfrom the original on 29 January 2020. Retrieved 30 January 2020.

15. Murphy, FA; Gibbs, EPJ; Horzinek, MC; Studdart MJ (1999). Veterinary Virology. Boston: Academic Press. pp. 495-508.
16. Wertheim JO, Chu DK, Peiris JS, Kosakovsky Pond SL, Poon LL (June 2013). "A case for the ancient origin of coronaviruses". Journal of Virology. 87 (12): 7039-7045.

17. "Transmission of Novel Coronavirus (2019-nCoV) | CDC". www. cdc.gov. 31 January 2020. Retrieved 1 February 2020.

18. What is 'gastro' coronavirus and what are the symptoms? The Metro 23 April 2020. https://metro.co.uk/2020/04/23/coronaviru s-uk-gastro-coronavirus-real- symptoms12599449/? ito=cbshare (Accessed 30 April 2020) Joint GI Society. COVID-19 Clinical

19. Jump up to:a b Forgie $S$, Marrie TJ (February 2009). "Healthcare-associated atypical pneumonia". Seminars in Respiratory and Critical Care Medicine. 30 (1): 67-85.

20. "Pneumonia of unknown cause - China". World Health Organization. 5 January 2020. Archived from the original on 7 January 2020. Retrieved 23 January 2020.

21. "New SARS-like virus found in Middle East". Al-Jazeera. 24 September 2012. Archived from the original on 9 March 2013. Retrieved 16 March 2013.

22. Insights for Our Community of Gastroenterologists and Gastroenterology Care Providers. 15 March 2020. Available from: https:// gi.org/ 2020/03/ 15/joint-

gi-society- me s s a ge - on - covid-19/ (Accessed 30 April 2020)

23. Zhang C, Shi L, Wang FS. Liver injury in COVID-19: management and challenges. Lancet Gastroenterol Hepatol 2020; $5: 428$.

24. Falco M (24 September 2012). "New SARS-like virus poses medical $\mathrm{m}$ y $\mathrm{s}$ tery". CNN Health. Archived from the original on 1 November 2013.Retrieved 16 March 2013. 
25. Zhang $H$, Kang $Z$, Gong $H$, et al. The digestive system is a potential route of 2019-nCov infection: A bioinformatics analysis based on single-cell transcriptomes. bioRxiv. Published on line January 31, 2020. (https:// doi.org/10.1101/2020.01.30.927806).

26. To KK, Tsang OT, Leung WS, et al. Temporal profiles of viral load in posterior oropharyngeal saliva samples and serum antibody responses during infection by SARS-CoV-2: an observational cohort study. Lancet Infect Dis 2020.

27. To KK, Hung IF, Ip JD, et al. COVID-19 re-infection by a phylogenetically distinct SARS-coronavirus-2 strain confirmed by whole genome sequencing. Clin Infect Dis (August 25, 2020), ciaa1275, https:// doi.org/10. 1093/cid/ ciaa1275 external icon.

28. Tillett R, Sevinsky J, Hartley $P$, et al. Genomic Evidence for a Case of Reinfection with SARS-CoV-2 (August 27, 2020). Available at S SRN:https://ssrn.com/abstract $=3680955$ externalicon or http://dx.doi.org/ 10.2139/ssrn. 3680955external icon

29. Young BE, Ong SWX, Kalimuddin S, et al. Epidemiologic Features and Clinical Course of Patients Infected With SARS-CoV-2 in Singapore. i 2020.

30. Wu Z, McGoogan JM. Characteristics of and Important Lessons From the Coronavirus Disease 2019 (COVID-19) Outbreak in China: Summary of a Report of 72314 Cases From the Chinese Center for Disease Control and Prevention. JAMA 2020.

31. Zhao J, Yuan $Q$, Wang $H$, et al. Antibody responses to SARS-CoV- 2 in patients of novel coronavirus disease 2019. Clin Infect Dis 2020.

32. Guo L, Ren L, Yang S, et al. Profiling Early Humoral Response to DiagnoseNovel Coronavirus Disease (COVID-19).Clin Infect Dis 2020
33. Wang W, Xu Y, Gao R, et al. Detection of SARS-CoV-2 in Different Types of Clinical Specimens. JAMA 2020.

34. Wu Y, Guo C, Tang L, et al. Prolonged presence of SARS-CoV-2 viral RNA in faecalsamples.LancetGastroenterol Hepatol2020;5:434-5.

35. Chen $W$, Lan $Y$, Yuan X, et al. Detectable 2019-nCoV viral RNA in blood is a strong indicator for the further clinical severity. Emerg Microbes Infect 2020;9:469-73.

36. Ding $Q$, Lu P, Fan Y, Xia Y, Liu M. The clinical characteristics of pneumonia patients coinfected with 2019 novel coronavirus and influenza virus in Wuhan, China. J Med Virol 2020.

37. Liu W, Zhang Q, Chen J, et al. Detection of Covid-19 in Children in Early January 2020 in Wuhan, China. N Engl J Med 2020; 382:1370-1.

38. Zhang C, Shi L, Wang FS. Liver injury in COVID-19: management and challenges. Lancet GastroenterolHepatol 2020; 5:428-30.

39. Qin C, Zhou L, Hu Z, et al. Dysregulation of immune response in patients with COVID-19 in Wuhan, China. Clin Infect Dis 2020.

40. Shi H, Han X, Jiang N, et al. Radiological findings from 81 patients with COVID-19 pneumonia in Wuhan, China: a descriptive study. Lancet Infect Dis 2020.

41. Guan WJ, Ni ZY, Hu Y, et al. Clinical Characteristics of Coronavirus Disease 2019 in China. N Engl J Med 2020; 382:1708-20.

42. Huang C, Wang $\mathrm{Y}, \mathrm{Li} \mathrm{X}$, et al. Clinical features of patients infected with 2019 novel coronavirus in Wuhan, China. Lancet 2020;395:497-506.

43. Wang D, Hu B, Hu C, et al. Clinical Characteristics of 138 Hospitalized Patients 22. With 2019 Novel Coronavirus-Infected Pneumonia in Wuhan, China. JAMA 
2020.

44. Wu C, Chen X, Cai Y, et al. Risk Factors Associated With Acute Respiratory Distress Syndrome and Death in Patients With Coronavirus Disease 2019 P n e u monia in Wuhan, China. JAMA Intern Med 2020.

45. Ai T, Yang Z, Hou H, et al. Correlation of Chest CT and RT-PCR Testing in Coronavirus Disease 2019 (COVID-19) in China: A Report of 1014 Cases.Radiology 2020: 200642.

46. Chen N, Zhou M, Dong X, et al. Epidemiological and clinical characteristics of 99 cases of 2019 novel coronavirus pneumonia in Wuhan, China: a descriptive study. Lancet 2020;395:507-13.

47. Bernheim A, Mei X, Huang M, et al. Chest CT Findings in Coronavirus Disease-19 (COVID-19): Relationship to Duration of Infection. Radiology 2020:200463.

48. Lei J, Li J, Li X, Qi X. CT Imaging of the 2019 Novel Coronavirus (2019-nCoV) Pneumonia. Radiology 2020;295:18.
49. Shi H, Han X, Zheng C. Evolution of CT Manifestations in a Patient Recovered from 2019 Novel Coronavirus (2019nCoV)Pneumonia in Wuhan, China. Radiology 2020;295:20.

50. Inciardi RM, Lupi L, Zaccone G, et al. Cardiac Involvement in a Patient With Coronavirus Disease 2019 (COVID-19). JAMA Cardiol 2020.

51. Wang $\mathrm{Y}$, Dong $\mathrm{C}, \mathrm{Hu} \mathrm{Y}$, et al. Temporal Changes of CT Findings in 90 Patients with COVID-19 Pneumonia: A Longitudinal Study. Radiology 2020:200843.

52. Shi S, Qin M, Shen B, et al. Association of Cardiac Injury With Mortality in Hospitalized Patients With COVID-19 in Wuhan, China. JAMA Cardiol 2020.

53. Xu X, Yu C, Qu J, et al. Imaging and clinical features of patients with 2019 novel coronavirus SARS-CoV-2. Eur J Nucl Med Mol Imaging 2020;47:1275-80.

54. Tang N, Bai H, Chen X, Gong J, Li D, Sun $Z$. Anticoagulant treatment is associated with decreased mortality in severe coronavirus disease 2019 patients with coagulopathy. J ThrombHaemost 2020. 